The Journal of Animal \& Plant Sciences, 31(2): 2021, Page: 352-357

ISSN (print): 1018-7081; ISSN (online): 2309-8694

\title{
REPRODUCTIVE PERFORMANCE OF FOUR VARIETIES OF INDIGENOUS ASEEL CHICKEN UNDER DIFFERENT REARING SYSTEMS
}

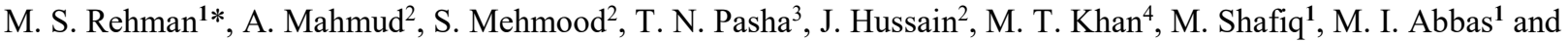 \\ M. A. Akram ${ }^{1}$ \\ ${ }^{1}$ Livestock and Dairy Development Department, Poultry Research Institute, Rawalpindi-46300, Pakistan; ${ }^{2}$ Department of \\ Poultry Production, University of Veterinary and Animal Sciences, Lahore-54000, Pakistan; ${ }^{3}$ University of Education, \\ Lahore-54000, Pakistan; ${ }^{4}$ Department of Poultry Science, Cholistan University of Veterinary and Animal Sciences, \\ Bahawalpur-63100, Pakistan. \\ *Corresponding author's email: pdomultan@gmail.com
}

\begin{abstract}
A study was undertaken to investigate the effect of three rearing systems (free range, semi-intensive and confinement) on reproductive performance in four varieties of indigenous Aseel chicken (Lakha, Mushki, Peshawari and Sindhi). A total of 192 adult birds (168 females and 24 males), 48 from each variety, were subjected to 3 rearing systems under Randomized Complete Block Design (RCBD) in a factorial experiment. Data regarding reproductive performance [settable eggs (\%), fertility (\%), hatch of fertile (\%), hatchability (\%), embryonic mortality (\%) and A-grade chicks (\%)] were recorded from 31 to 46 weeks of age. The collected data were analyzed by using ANOVA technique. The results demonstrated improved settable eggs, fertility and hatchability in hens reared under confinement and semi-intensive rearing systems. Among different varieties, Sindhi and Peshawari hens depicted higher settable eggs (95.41 \pm 0.54$)$ and A-grade chicks (59.36 \pm 2.57$)$, respectively. Interaction of rearing systems and varieties clearly indicated maximum settable eggs in both Sindhi and Peshawari hens reared under confinement rearing system. Fertility and hatchability were greater $(\mathrm{P} \leq 0.05)$ in Sindhi hens under semi-intensive rearing system. The highest $(\mathrm{P} \leq 0.05)$ A-grade chicks $(63.59 \pm 4.68)$ were found in Peshawari hens under semi-intensive rearing system. From the findings, it can be concluded that confinement and semi-intensive rearing systems remained comparatively better with respect to settable eggs, fertility and hatchability. Both Sindhi and Lakha varieties of Aseel hens can be raised in semi-intensive rearing system as they demonstrated better performance with respect to settable eggs and A-grade chicks.
\end{abstract}

Key words: Aseel chicken, Reproductive performance, Rearing systems.

https://doi.org/10.36899/JAPS.2021.2.0222

Published online October 03,2020

\section{INTRODUCTION}

Profitability of hatchery industry depends on fertility and hatchability of breeder flocks producing viable chicks. Both these factors are the major constraints, which depends on genetics and physiology of chicken breed, affecting proliferation of progeny. The performance parameters of breeder flock, regarding final body weight, egg production, fertility, and hatchability depend on highest inputs in different housing systems (Ahmad, 2019). The native chickens are reared in rural areas of Pakistan, which are a source of premium quality protein, generate income, and contribute to the national GDP as well (Anonymous, 2018-19).

In recent years, free-range poultry production has gained much popularity due to increasing consumers interest (Chen et al., 2013). Free-range or outdoor rearing systems are widely encouraged as being natural and animal welfare friendly (Brown et al., 2008; Husak et al., 2008). These systems provide natural and stimulating environment to the hens with reduced stocking density, improving the overall welfare of the flocks (Fanatico and
Born, 2001; Sundrum, 2001; Brown et al., 2008; Hegelund et al., 2006). Additionally, free range systems help in mitigating the stressful conditions and increase birds' comfort (Blokhuis et al., 2000), most probably due to more exercise and walking ability (Fanatico et al., 2005, Fanatico, 2008). Outdoor rearing systems are ideally covered with vegetation where birds have complete freedom for scavenging, feed selection and other similar activities that improve their welfare and comfort (Ponte et al., 2008; Chen et al., 2013). These systems, moreover, help in the expression of their natural behaviour, which otherwise seems impossible in totally confined systems (Zelnter and Maurer, 2009).

Ideally, slow-growing chicken such as indigenous poultry (Magala et al., 2012) can only benefit from a free range or outdoor system (Reiter and Bessei, 1998; Castellini et al., 2002; Branciari et al., 2009). In developing countries, rural poultry production is mainly based on small flocks of scavenging birds (FAO, 2004), which are relatively sturdy in nature and have ability to survive on inadequate feed resources in local climatic conditions (FAO, 2004; Khan, 2015) under the traditional 
free range system (Mekria and Gezahegn, 2010). Therefore, these birds or indigenous poultry has key role in the sustenance of various rural communities (Faouzi et al., 2002; Mekria and Gezahegn, 2010). However, fastgrowing birds, which are selected for better growth rate, tend to stay indoors rather than go outdoors to reduce energy cost (Branciari et al., 2009). Furthermore, under intensive rearing system birds have no access to green pastures enriched with vitamins that play a significant role in improving the reproductive efficiency of birds (Okeno et al., 2010).

Aseel being hardy with the ability to thrive in harsh environmental conditions might be the aspirant germplasm for improvement through selective breeding. Production of low input free range poultry can be enhanced by introducing the improved Aseel varieties in countryside to earn livelihoods (Haunshi et al., 2019). Aseel is one of the major breeds among indigenous poultry in Indo-Pak subcontinent. It is widely recognized due to its sturdiness and adaptability in extreme climatic conditions (Khan, 2015). The present study was planned to evaluate the effects of three different rearing systems on overall reproductive performance in four varieties of indigenous Aseel chicken in Pakistan.

\section{MATERIALS AND METHODS}

Experimental site: The present study was conducted at Indigenous Chicken Genetic Resource Centre (ICGRC), Department of Poultry Production, University of Veterinary and Animal Sciences, Ravi campus, Pattoki, Lahore for the duration of 16 weeks (31-46 weeks).

Experimental birds: A total of 192 adult birds (168 females and 24 males) from four varieties of indigenous Aseel (Lakha, Mushki, Peshawari and Sindhi), 48 (42+ $\left.6{ }^{3}\right)$ from each variety, at the age of thirty weeks were randomly divided into three treatment groups (free range, semi-intensive and confinement) and replicated 14 times with individual hen in each replicate under Randomized Complete Block Design (RCBD) in a factorial arrangement. Two males were assigned to 14 females in each experimental group.

Housing management: Experimental birds were maintained in an independent open-sided poultry house (dimension $20 \times 20$ feet) under standard environmental conditions. The birds under confinement rearing system were maintained in three-tier laying cages with sloping wire floor to facilitate egg collection. The removable dropping trays were fitted under the mesh floor for removal of fecal material. Hens were kept separately in individual cages to get the separate record of every hen regarding egg production. Feed and water were provided through removable trough feeders installed in front of cage and automatic nipple drinking system, respectively. Floor space of 1.5 square feet was provided to each hen.
Feeding management: In cages, male and female birds were offered male and female broiler breeder rations, respectively following the nutrient requirements of parent stocks according to the recommendations of NRC (1994). Birds under semi-intensive rearing system were kept half day in cages with $50 \%$ feed allowance in the evening $(6: 00 \mathrm{pm})$ according to standard scale and half day in free range area (9:00 am to 1:00 pm) enriched with seasonal fodders (legumes, beans, lentils, it-sit, herbs and grass). However, hens under free range system had whole day access to free range area (9:00 am to 5:00 pm) with 25\% feed allowance $(6: 00 \mathrm{pm})$ and at the end of the day, they used to be kept on floor in the same house with litter as bedding material. In free range area, replication was done with the help of fish net each having one nest box for egg laying. Hen in each replicate was tagged to get separate record for egg production. Water was also provided outdoors using water pans with reservoirs. To keep the predators away from the experimental birds, wire mesh fencing of eight feet height was provided around the free range area.

Mating system: Stud mating system was practiced, in which each hen had access to one male in the same group once a week (one hen/cock/20hrs.). The eggs were collected and set in the incubator in eight batches under standard conditions of incubation to study hatching traits. Every batch comprised fortnight collection.

Data collection: Daily egg production was recorded to calculate fortnightly settable eggs. At the end of each hatch, fertility, hatchability, embryonic mortality and Agrade chicks' percent was calculated through break out analysis. Hatch of fertile was calculated by dividing total chicks hatched over total fertile eggs.

Statistical analysis: The data regarding reproductive performance of Aseel chicken were collected and subjected to Analysis of Variance (ANOVA) technique under factorial arrangements using SAS 9.1 (2002-03). Means among treatments were compared through Duncan's Multiple Range (DMR) test (Duncan, 1955). The statistical model used was:

$Y i j k=\mu+\mathrm{Vi}+\mathrm{Rj}+(\mathrm{V} \times \mathrm{R}) \mathrm{ij}+\varepsilon i j k$

Where Yijk is the kth observation of the ith bird $(\mathrm{V})$ in the $j$ th rearing system $(\mathrm{R}),(\mathrm{V} \times \mathrm{R}) \mathrm{ij}$ is the interaction of Aseel variety and rearing system. $\mu$ is the overall mean and eijk is the residual error associated with Yijk observation.

\section{RESULTS AND DISCUSSION}

Settable eggs (\%): Different rearing systems, varieties as well as their interaction revealed clinical difference in settable eggs. Hens under confinement rearing system produced higher settable eggs $(95.90 \pm 0.48)$ than those under semi-intensive $(93.87 \pm 0.78)$ and free range rearing 
systems $(92.06 \pm 0.74)$. This might be attributed to the various factors including proper diet and minimum disturbance during laying process in confinement rearing system. Among different varieties, hens of Sindhi Aseel indicated higher settable eggs $(95.41 \pm 0.54)$ compared to those of Mushki (93.02 \pm 0.95$)$. This discrepancy in settable eggs might be attributed to the genetic variation in different varieties as it has already been claimed that settable eggs vary due to strain effect (Renema et al., 2001). Similarly, a recent study conducted on Aseel also displayed disparity in settable eggs (Khan, 2015). Interaction of different rearing systems with varieties displayed maximum settable eggs (96.52 \pm 0.61$)$ in Peshawari hens under confinement rearing system.

Fertility (\%): Fertility was found to be vary with respect to different rearing systems and their interaction with different varieties. Remarkable improvement in fertility was observed in hens reared under semi-intensive $(81.27 \pm 1.15)$ and confinement $(79.00 \pm 0.82)$ rearing systems compared to free range $(74.00 \pm 1.35)$. Balanced diet, better management and somewhat moderate temperature in confinement might be the motives behind improved fertility as it is believed that fertility of poultry breeding stock is improved due to proper management (Udeh and Omeje, 2014). On the contrary, in free range area, high temperature, poor management practices, mating behaviour and nutrients deficiency may adversely affect the fertility (Hocking et al., 2007). A study on turkeys, likewise, claimed highest fertility under intensive rearing system followed by semi-intensive and free range (Anandh et al., 2012).

Varieties, however, independently could not show any influence on fertility, which can be explained by the fact that genotype might have no effect on fertility (Shafik et al., 2013). Interaction of rearing systems with varieties displayed maximum fertility in Sindhi under semi-intensive rearing system $(83.79 \pm 1.98)$.

Hatch of fertile (\%): All treatments separately as well as during their interaction with each other demonstrated no clear difference in hatch of fertile. Hatch of fertile showed no variations with respect to various Aseel varieties. Similar response of different breeds on hatch of fertile has already been claimed (Alsobayel and Albadry, 2012) showing that there was no correlation between hatch of fertile and different genotypes (Shafik et al., 2013) or phenotype of poultry (Bobbo et al., 2013). Different rearing systems indicated no difference in hatch of fertile. However, a study on turkeys presented facts other way round and reported variations in hatch of fertile showing highest value of it in intensive system followed by semi-intensive and free range system (Anandh et al., 2012).

Hatchability (\%): Variations were found in hatchability regarding different rearing systems and their interaction with different Aseel varieties. However, varieties independently could not demonstrate variations in hatchability. Hens reared under semi-intensive $(60.27 \pm 1.19)$ and confinement $(59.18 \pm 0.79)$ rearing systems indicated improved hatchability than those of free range $(52.64 \pm 1.21)$. In the same trial, better fertility under semi-intensive and confinement systems might have caused improvement in hatchability. Some earlier studies, likewise, reported amelioration in hatchability under confinement rearing system (Anandh et al., 2012) showing positive correlation between intensive rearing system and hatchability (Kugonza et al., 2012). In interaction of rearing systems with varieties, Sindhi hens once again appeared to be the best demonstrating maximum hatchability $(83.79 \pm 1.98)$ under semi-intensive rearing system.

Embryonic mortality (\%): All treatments separately and interacting with each other revealed no significant $(\mathrm{P}>0.05)$ difference in embryonic mortality. It was, similarly, claimed that breed had no effect on embryonic mortality (Alsobayel and Albadry, 2012). In the current study, difference in embryonic mortality was nonsignificant with respect to different rearing systems. Contrary to this, highest percentage of embryonic mortality was noticed under free range followed by semiintensive and confinement (Anandh et al., 2012). In turkeys, the highest embryonic mortality was detected in intensive than semi-intensive and free range rearing systems (Anandh et al., 2012). A study conducted to probe the effect of two housing systems on quails, revealed lower embryonic mortality in floor pens than in battery cages (Roshdy et al., 2010).

A-grade chicks (\%): Varieties alone and in combination with different rearing systems showed fluctuations in overall means of A-grade chicks whereas no clinical difference was found with respect to different rearing systems. A-grade chicks percent was found to be greater $(59.36 \pm 2.57)$ in Peshawari hens than Sindhi

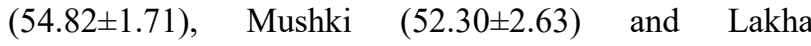
$(52.76 \pm 1.89)$ hens. This difference in A-grade chicks might be linked with the variations in genetic make-up of different Aseel varieties. Discrepancies in A-grade chicks were also found in a study on Aseel varieties (Khan, 2015). Interaction of rearing systems and varieties clearly indicated higher A-grade chicks (63.59 \pm 4.68$)$ from the Peshawari hens under semi-intensive rearing system. 
Table 1: Overall reproductive performance in four varieties of Aseel under three rearing systems (31-46 weeks).

\begin{tabular}{|c|c|c|c|c|c|c|c|}
\hline $\begin{array}{l}\text { Parameter } \\
\text { Variable }\end{array}$ & & $\begin{array}{c}\text { Settable eggs } \\
(\%)\end{array}$ & $\begin{array}{l}\text { Fertility } \\
(\%)\end{array}$ & $\begin{array}{l}\text { Hatch of fertile } \\
\qquad(\%)\end{array}$ & $\begin{array}{c}\text { Hatchability } \\
(\%)\end{array}$ & $\begin{array}{c}\text { Embryonic } \\
\text { mortality (\%) }\end{array}$ & $\begin{array}{c}* \text { A-grade chicks } \\
(\%)\end{array}$ \\
\hline & \multicolumn{7}{|c|}{ Rearing systems } \\
\hline Free range & & $92.06 \pm 0.74^{\mathrm{b}}$ & $74.00 \pm 1.35^{\mathrm{b}}$ & $72.29 \pm 1.38$ & $52.64 \pm 1.21^{\mathrm{b}}$ & $21.74 \pm 1.19$ & $54.05 \pm 2.26$ \\
\hline Semi-intensive & & $93.87 \pm 0.78^{b}$ & $81.27 \pm 1.15^{\mathrm{a}}$ & $74.89 \pm 0.95$ & $60.27 \pm 1.19^{\mathrm{a}}$ & $20.76 \pm 0.65$ & $55.15 \pm 1.96$ \\
\hline \multirow[t]{2}{*}{ Confinement } & & $95.90 \pm 0.48^{\mathrm{a}}$ & $79.00 \pm 0.82^{\mathrm{a}}$ & $74.86 \pm 0.94$ & $59.18 \pm 0.79^{a}$ & $19.69 \pm 0.76$ & $55.23 \pm 1.70$ \\
\hline & \multicolumn{7}{|c|}{ Varieties } \\
\hline Lakha & & $93.40 \pm 0.98^{\mathrm{ab}}$ & $76.53 \pm 1.65$ & $74.13 \pm 1.58$ & $55.91 \pm 1.66$ & $20.62 \pm 1.13$ & $52.76 \pm 1.89^{\mathrm{ab}}$ \\
\hline Mushki & & $93.02 \pm 0.95^{\mathrm{b}}$ & $78.29 \pm 1.26$ & $74.17 \pm 1.19$ & $57.53 \pm 1.37$ & $20.82 \pm 0.95$ & $52.30 \pm 2.63^{\mathrm{b}}$ \\
\hline Peshawari & & $93.95 \pm 0.77^{\mathrm{ab}}$ & $78.88 \pm 1.38$ & $72.87 \pm 1.20$ & $57.22 \pm 1.24$ & $21.44 \pm 1.13$ & $59.36 \pm 2.57^{\mathrm{a}}$ \\
\hline \multirow[t]{3}{*}{ Sindhi } & & $95.41 \pm 0.54^{\mathrm{a}}$ & $78.66 \pm 1.43$ & $74.89 \pm 1.21$ & $58.80 \pm 1.38$ & $20.05 \pm 0.99$ & $54.82 \pm 1.71^{\mathrm{ab}}$ \\
\hline & \multicolumn{7}{|c|}{ Rearing systems $\times$ Varieties } \\
\hline & Lakha & $88.93 \pm 1.38^{\mathrm{d}}$ & $71.36 \pm 3.14^{\mathrm{d}}$ & $71.80 \pm 4.07$ & $50.23 \pm 2.92^{\mathrm{e}}$ & $21.13 \pm 2.86$ & $53.12 \pm 4.65^{\mathrm{ab}}$ \\
\hline \multirow[t]{4}{*}{ Free range } & Mushki & $92.95 \pm 1.73^{\mathrm{abc}}$ & $74.76 \pm 1.86^{\mathrm{bcd}}$ & $70.31 \pm 2.36$ & $51.57 \pm 2.41^{\mathrm{de}}$ & $23.38 \pm 2.10$ & $50.00 \pm 5.50^{\mathrm{b}}$ \\
\hline & Peshawari & $91.54 \pm 0.97^{\mathrm{bcd}}$ & $76.40 \pm 3.41^{\mathrm{abcd}}$ & $71.49 \pm 1.88$ & $54.02 \pm 1.84^{\text {cde }}$ & $23.16 \pm 2.53$ & $59.17 \pm 5.44^{\mathrm{ab}}$ \\
\hline & Sindhi & $94.83 \pm 1.11^{\mathrm{abc}}$ & $73.48 \pm 2.29^{\mathrm{cd}}$ & $75.54 \pm 2.49$ & $54.76 \pm 2.55^{\text {bcde }}$ & $19.30 \pm 2.14$ & $53.90 \pm 1.77^{\mathrm{ab}}$ \\
\hline & Lakha & $95.60 \pm 1.56^{\mathrm{ab}}$ & $79.98 \pm 2.98^{\mathrm{abc}}$ & $75.67 \pm 1.12$ & $59.67 \pm 3.00^{\mathrm{abc}}$ & $20.31 \pm 0.86$ & $50.70 \pm 2.89^{\mathrm{ab}}$ \\
\hline \multirow[t]{4}{*}{ Semi-intensive } & Mushki & $91.08 \pm 1.68^{\mathrm{cd}}$ & $79.14 \pm 2.31^{\mathrm{abc}}$ & $76.80 \pm 1.94$ & $59.58 \pm 1.68^{\mathrm{abc}}$ & $19.55 \pm 1.39$ & $55.07 \pm 3.96^{\mathrm{ab}}$ \\
\hline & Peshawari & $93.78 \pm 1.67^{\mathrm{abc}}$ & $82.17 \pm 1.85^{\mathrm{ab}}$ & $71.32 \pm 2.18$ & $58.47 \pm 2.72^{\mathrm{abcd}}$ & $22.75 \pm 1.48$ & $63.59 \pm 4.68^{a}$ \\
\hline & Sindhi & $95.03 \pm 1.00^{\mathrm{abc}}$ & $83.79 \pm 1.98^{a}$ & $75.78 \pm 1.94$ & $63.36 \pm 1.98^{\mathrm{a}}$ & $20.42 \pm 1.40$ & $51.23 \pm 2.70^{\mathrm{ab}}$ \\
\hline & Lakha & $95.67 \pm 0.94^{\mathrm{ab}}$ & $78.25 \pm 1.54^{\mathrm{abcd}}$ & $74.90 \pm 2.36$ & $57.82 \pm 1.62^{\mathrm{abcd}}$ & $20.42 \pm 1.93$ & $54.45 \pm 2.09^{\mathrm{ab}}$ \\
\hline \multirow[t]{3}{*}{ Confinement } & Mushki & $95.03 \pm 1.45^{\mathrm{abc}}$ & $80.97 \pm 2.02^{\mathrm{abc}}$ & $75.39 \pm 1.18$ & $61.45 \pm 1.41^{\mathrm{ab}}$ & $19.51 \pm 1.07$ & $51.83 \pm 4.50^{\mathrm{ab}}$ \\
\hline & Peshawari & $96.52 \pm 0.61^{\mathrm{a}}$ & $78.06 \pm 1.17^{\mathrm{abcd}}$ & $75.80 \pm 2.05$ & $59.17 \pm 1.50^{\mathrm{abc}}$ & $18.42 \pm 1.43$ & $55.31 \pm 2.98^{\mathrm{ab}}$ \\
\hline & Sindhi & $96.38 \pm 0.73^{\mathrm{a}}$ & $78.71 \pm 1.84^{\mathrm{abcd}}$ & $73.35 \pm 2.01$ & $58.28 \pm 1.79^{\mathrm{abcd}}$ & $20.42 \pm 1.71$ & $59.33 \pm 3.70^{\mathrm{ab}}$ \\
\hline
\end{tabular}

Note: Different superscripts on means in columns show significant $(\mathrm{P} \leq 0.05)$ differences

*Chicks weighing above $35 \mathrm{gm}$ without physical deformity 
Conclusions: Based on the findings of this experiment, it can be concluded that among three rearing systems, confinement and semi-intensive rearing systems remained comparatively better in terms of settable eggs, fertility and hatchability. Among different Aseel varieties, Sindhi and Peshawari hens showed better performance in terms of settable eggs and A-grade chicks. Interaction of rearing systems and varieties clearly demonstrated that Sindhi hens when reared under confinement and semi-intensive rearing systems produced maximum settable eggs with the highest fertility and hatchability whereas Peshawari hens showed maximum settable eggs under confinement and the highest A-grade chicks under semi-intensive rearing system.

Acknowledgements: The authors gratefully acknowledge the cooperation extended by administration of Indigenous Chicken Genetic Resource Center (ICGRC), Department of Poultry Production, UVAS, Ravi Campus, Pattoki, especially Late Prof. Dr. Muhammad Akram, for facilitating and funding the present study.

\section{REFERENCES}

Ahmad, S. (2019). Performance of Rhode Island Red, Black Australorp and Naked Neck Crossbred under free range, semi intensive and intensive housing systems. Ph.D. Thesis, Dept. Poultry Prod., UVAS, Lahore.

Alsobayel, A. A. and M. A. Albadry (2012). Effect of age and sex ratio on fertility and hatchability of Baladi and Leghorn laying hens. The J. Anim. \& Plant Sci., 22(1): 15-19.

Anandh, M. A., P. N. R. Jagatheesan, P. S. Kumar, A. Paramasivam and G. Rajarajan (2012). Effect of rearing systems on reproductive performance of turkey. Vet. World. 5(4): 226-229.

Anonymous. (2018-19). Economic Survey of Pakistan. Ministry of Food and Agriculture Division (Economic Wing). Agriculture, Chapter 2. III. Livestock and Poultry. b. Poultry. 28 p.

Blokhuis, H., E. Ekkel, S. Korte, H. Hopster and C. Van Reenen (2000). Farm animal welfare research in interaction with society. Vet. Q. 22(4):217-222.

Bobbo, A. G., M. S. Yahaya and S. S. Baba (2013). Comparative assessment of fertility and hatchability traits of three phenotypes of local chickens in Adamawa State. J. Agric Vet. Sci., 4(2): 22-28.

Branciari, R., C. Mugnai, R. Mammoli, D. Miraglia, D. Ranucci, A. Dal Bosco and C. Castellini (2009). Effect of genotype and rearing system on chicken behavior and muscle fiber characteristics. J. Anim. Sci., 87(12): 41094117.

Brown, S. N., G. R. Nute, A. Baker, S. I. Hughes and P. D. Warriss (2008). Aspects of meat and eating quality of broiler chickens reared under standard, maize-fed, free range or organic systems. Brit. Poult. Sci., 49 (2): 118-124.

Castellini, C., C. Mugnai and A. Dal Bosco (2002). Effect of organic production system on broiler carcass and meat quality. Meat Sci., 60(3): 219225.

Chen, X., W. Jiang, H. Z. Tan, G. F. Xu, X. B. Zhang, S. Wei and X. Q. Wang (2013). Effects of outdoor access on growth performance, carcass composition, and meat characteristics of broiler chickens. Poult. Sci. 92(2): 435-443.

Duncan, D. B. (1955). Multiple ranges and multiple F tests, Biometrics. 11:1.

Fanatico, A. (2008). Organic poultry production in the United States. National Center for Appropriate Technology (NCAT). ATTRA. www.attra.ncat.org/attrapub/PDF/organicpoultry.pdf.

Fanatico, A. and H. Born (2001). Label Rouge: PastureRaised Poultry in France. ATTRA Publication. Natl. Center Appropriate Technol., Fayetteville, AR.

Fanatico, A. C., L. C. Cavitt, P. B. Pillai, L. C. Cavitt, J. L. Emmert and C. M. Owens (2005). Evaluation of slower growing broiler genotypes grown with and without outdoor access: meat quality. Poult. Sci., 84(11): 1785-1790.

FAO. 2004. Small-scale poultry production-technical guide by E. B. Sonaiya and S. E. J. Swan. FAO Animal Production and Health Manual, Rome, FAO. $119 \mathrm{p}$.

Faouzi, K., N. E. Omari, N. Tmiri and T. Jaouzi (2002). Health and management constraints to family poultry development in Morocco. In: Characteristics and parameters of family poultry production in Africa. In: Proceedings of the research coordination meeting of IAEA, Morogoro, Tanzania in September, 2000. pp: 73-85.

Haunshi, S., U Rajkumar and M. K. Padhi (2019). Improvement of PD-4 (Aseel), an indigenous chicken, for growth and production traits. Ind. J. Anim. Sci., 89(4): 419-423.

Hegelund, L., J. T. Sorensen and J. E. Hermansen (2006). Welfare and productivity of laying hens in commercial organic egg production systems in Denmark. NJAS, 54(2): 147-155.

Hocking, P. M., G.W. Robertson and D. Teverson (2007). Fertility and early embryonic mortality in traditional breeds of chicken in the UK. In. Proc. 
$5^{\text {th }}$ European Poultry Genetic Symposium, Braedstrup, Denmark, pp. 108.

Husak, R., J. Sebranek and K. Bregendahl (2008). A survey of commercially available broilers marketed as organic, free-range, and conventional broilers for cooked meat yields, meat composition, and relative value. Poult. Sci., 87(11): 2367-2376.

Khan, M. T. (2015). Effects of selenium-supplemented diets on production performance, hatching, egg geometry and quality traits in four varieties of indigenous Aseel. M. Phil. Theses (Poultry Production), UVAS, Lahore, Pakistan.

Kugonza, D. R., G. Kirembe, E. Tomusange-Nvule, R. Lutalo and E. Drani (2012). Experimental validation of farmer innovations in incubation and brooding management of chickens. Livestock Research for Rural Development, 24(5): 1-7.

Magala, H., D. R. Kugonza, H. Kwizera and C. C. Kyarisiima (2012). Influence of management system on growth and carcass characteristics of Ugandan local chickens. J. Anim. Sci. Adv., 2(6): 558-567.

Mekuria, S. and E. Gezahegn (2010). Prevalence of external parasites of poultry in intensive and backyard chicken farm at Wolayta Saddo town, Southern Ethiopia. Vet. World, 3(12): 533-538.

NRC. (1994). Nutrient requirements of poultry. National Academy Press, Washington, DC.

Okeno, T. O., A. K. Kahi and J. K. Peters (2010). Characterization of indigenous chicken production systems in Kenya household flock structure, dynamics and breeding practices. Biennial conference paper. pp. 877-884.

Ponte, P. I. P., C. M. C. Rosado, J. P. Crespo and D. G. Crespo (2008). Pasture intake improves the performance and meat sensory attributes of freerange broilers. Poult. Sci., 87(1): 71-79.

Reiter, K. and W. Bessei (1998). Effect of locomotor activity on bone development and leg disorders in broilers. Archiv fur Geflugelkunde. 62(6): 247-253.

Renema, R. A., F. E. Robinson, J. J. R. Feddes, G. M. Fasenko and M. J. Zuidhof (2001). Effects of light intensity from photostimulation in four strains of commercial egg layers: 2. Egg production parameters. Poult. Sci., 80(8): 11211131.

Roshdy, M., H. A. Khalil, A. M. Hanafy and M. E. Mady (2010). Productive and reproductive traits of Japanese quail as affected by two housing system. Egypt. Poult. Sci., 30(1): 55-67.

SAS, 2002-03. SAS/STATE User's guide: Statistics. Version 9.1., SAS Institute Inc, Cary, North Carolina, USA.

Shafik, B. M. N., K. M. El-Bayomi, G. A. Sosa and A. M. R. Osman (2013). Effect of crossing Fayoumi and Rhode Island Red on growth performance, egg and reproductive traits under Egyptian conditions. Benha Vet. Med. J., 24(2): 11-18.

Sundrum, A. (2001). Organic livestock farming. A critical review. Livestock Production Science. 67(3): 207-215.

Udeh, I. and S. I. Omeje (2014). Hatching characteristics of local and exotic (egg type) chickens using a locally fabricated incubator. J. Biol. Agric. \& Healthcare. 4(16): 50-53.

Zelnter, E. and V. Maurer (2009). Welfare of organic poultry. Proceedings of 8th Poultry Welfare Symposium, Cervia, Italy, 18-22 May 2009, pp. 104-112. 